\title{
Estudio preliminar sobre el uso de «provisionales envolventes»
}

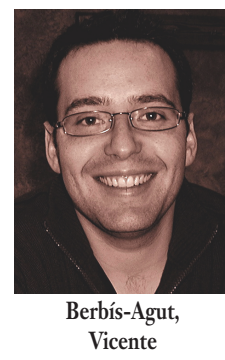

\author{
Preliminar studu about the use of «covering provisionals»
}

\section{Berbís-Agut, Vicente}

Odontólogo. Servicio de Estomatología del «Institut Universitari Dexeus». Dedicatoria exclusiva en prostodoncia. Práctica privada en Barcelona.

\section{Correspondencia}

Vicente Berbís Agut

Clínica Bonadex, S.L.

Po. Bonanova, $69-3^{\circ}$

08017 - Barcelona

E-mail: vicenteberbis@bonadexsl.com
Resumen: Introducción: Con este estudio preliminar se pretende mostrar que en el interior de la cavidad oral se producen cambios de presión que influyen sobre los tejidos, en base a la explicación neumática de P. Harster, y que con el uso de "provisionales envolventes" podemos aprovechar estos cambios para obtener mayor volumen gingival.

Material y método: Se explica la confección de un «provisional envolvente», cuyo objetivo es aumentar el volumen gingival. Se diseña y confecciona un dispositivo para la medición de cambios de presión en el interior del provisional, y se llevan a cabo los registros correspondientes.

Resultados: En cuanto a crecimiento gingival bajo el provisional envolvente, los resultados fueron positivos, observando incrementos de hasta $2 \mathrm{~mm}$ a las 3 semanas. En lo referente a cambios de presión intraoral, se registraron descensos sobre la basal en el interior del "provisional envolvente», variables en función de la maniobra realizada.

Conclusiones: En el interior de cavidades incolapsables y no herméticas delimitadas por «provisionales envolventes", y en continuidad con el medio oral, se producen variaciones de presión en torno a una basal, que se ponen de manifiesto bajo diversas maniobras como la deglución. Con el uso de "provisionales envolventes\% aprovechamos este vacío, pudiendo obtener crecimiento gingival controlado.

Palabras clave: Presión negativa, Provisional envolvente, Vacío intraoral, Papila, Crecimiento gingival, Manometría.

Abstract: Introduction: With this preliminary study it is sought to show that inside the oral cavity changes of pressure infludying the tissues take place, based on the pneumatic explanation of P. Harster, and also that using "covering provisionals» we can take advantage of these changes to obtain more gingival volume.

Material and Methods: The making of a "covering provisional» is explained, whose objective is to increase the gingival volume. A device for measuring changes of pressure inside this provisional was designed and made. All changes were registered.

Results: About gingival growth under the "covering provisional», the results were positive, observing increases that reach $2 \mathrm{~mm}$ in 3 weeks. Concerning changes of intraoral pressure, descents around thebasal one inside the "covering provisional» were registered, in relation of the carried out maneuver. Conclusions: Inside uncollapsables and not hermetic cavities defined by "covering provisionals", and in continuity with the oral cavity, variations of pressure take place around a basal one, and you can see them during several maneuvers as deglution. With the use of "covering provisionals" we take advantage of this vacuum, being able to obtain controlled gingival growth.

Key works: Negative pressure, Covering provisional, Intraoral vacuum, Papilla, Gingival growthl, Manometry.

\begin{tabular}{ccc}
\hline Fecha recepción & Fecha última revisión & Fecha aceptación \\
$24-10-2003$ & $24-1-2005$ & $15-3-2005$ \\
\hline
\end{tabular}

BIBLID [1138-123X (2005)10:2; marzo-abril 125-240]

Berbís-Agut, Vicente. Estudio preliminar sobre el uso de «provisionales envolventes». RCOE 2005;10(2):145-157. 


\section{Introducción}

Uno de los grandes retos a los que nos enfrentamos en nuestra profesión, es el de conseguir resultados estéticos, ya que cada vez son mayores las exigencias de nuestros pacientes a este respecto. El término estéti$\mathrm{ca}$, en odontología, va íntimamente ligado al de naturalidad, de modo que una prótesis estética es aquella que queda integrada dentro del marco de la sonrisa del paciente, y es menos estética cuanto más evidente es su presencia en boca.

Cuando tratamos de reponer dientes ausentes, nos encontramos con frecuencia ante un problema añadido, y es que las estructuras de soporte han sufrido cambios, siendo insuficiente la reposición de las piezas, para devolverle la estética al paciente.

Ante esta situación de pérdida dentaria ligada a pérdida de tejido óseo y gingival, la odontología ha aportado diversas alternativas según el caso, desde injertos óseos o de conectivo, hasta cerámicas rosas, resinas e incluso «encías» de quita y pon. Hay soluciones para todos los gustos, pero difícilmente alcanzan el nivel estético de la dentición natural.

Cuando partimos de una situación difícil al comenzar el tratamiento de prótesis, los pequeños avances estéticos suelen valorarse muy positivamente, no obstante, son las situaciones aparentemente más sencillas las que pueden crearle mayor grado de insatisfacción al paciente, al no poder eliminar, en el caso de prótesis fija, ciertos condicionantes estéticos como son los "triángulos negros" por ejemplo, debiendo recurrir en estos casos a confeccionar piezas con pun- tos de contacto muy gingivales, cerámicas simulando encía o injertos de conectivo si el defecto es más importante.

Con este estudio preliminar, se pretende iniciar una línea de experimentación en torno a la formación de papilas interdentales desde un punto de vista práctico y funcional, tomando como base la explicación de la «bomba neumática oral» formulada por Pere Harster ${ }^{1 * *}$ y diseñando una prótesis provisional que mantenga unas circunstancias propicias para la formación de tejido gingival en base a esta explicación neumática. Esto podría abrir puertas a nuevas experiencias en la materia, que nos permitieran establecer protocolos para mejorar los resultados estéticos.

La mucosa oral y el hueso de los maxilares están sujetos a cambios ante variaciones en el medio oral, como por ejemplo la perdida de dientes. Suelen aparecer en estos casos, desplazamientos dentarios, el hueso se remodela, y la encía que lo recubre se modifica con él, con los consiguientes condicionantes de cara a un próximo tratamiento, tanto funcionales como estéticos.

En la exploración oral observamos con frecuencia una serie de fenómenos a los que Harster ${ }^{1 *}$ dio una explicación de carácter neumático que los integra y que tomaremos como base. Según esta explicación neumática, cada deglución provoca una onda de presión negativa que estimula el crecimiento y la adaptación de los tejidos blandos sobre las estructuras duras, como por ejemplo la formación de crecimientos gingivales bajo elementos de retención situados en proximidad de la mucosa oral (ataches), cre- cimientos gingivales bajo prótesis fija que conforman el negativo de la estructura rígida a la que subyacen, crecimientos blandos en el frenillo labial, "papilas labiales», diapneusias, alteraciones linguales como la lengua dentada, etc.

La presencia de papila interdental va necesariamente ligada a la presencia de dientes, de modo que no se puede hablar de papila interdental en recién nacidos o desdentados totales. La papila adquiere una forma determinada, que guarda relación con la disposición del punto de contacto en relación con la cresta ósea, según se ha descrito en la literatura (Tarnow²). Según nuestra teoría, para que esta papila se pueda conformar, es necesario que se den unas condiciones de presión negativa efectiva determinadas. Es decir, que en cada deglución se genere un gradiente suficiente, y que la mucosa yugal o labial y la lengua no lleguen a colapsar la tronera (lo que podría ocurrir en casos de troneras demasiado amplias o de excesiva laxitud labial).

Tomando como base esta explicación funcional sobre los crecimientos gingivales y mucosos en la cavidad oral, se ideó la forma de conseguir una pequeña cavidad dentro del medio oral, incolapsable por los tejidos blandos (lengua y labios) pero no hermética (continuidad), de modo que "sufriera" las variaciones de presión que pudieran tener lugar en la boca, diseñando así una prótesis provisional con la que proporcionar las condiciones "óptimas» para la formación de tejido gingival, y con la que poder llevar a cabo nuestra experiencia. 


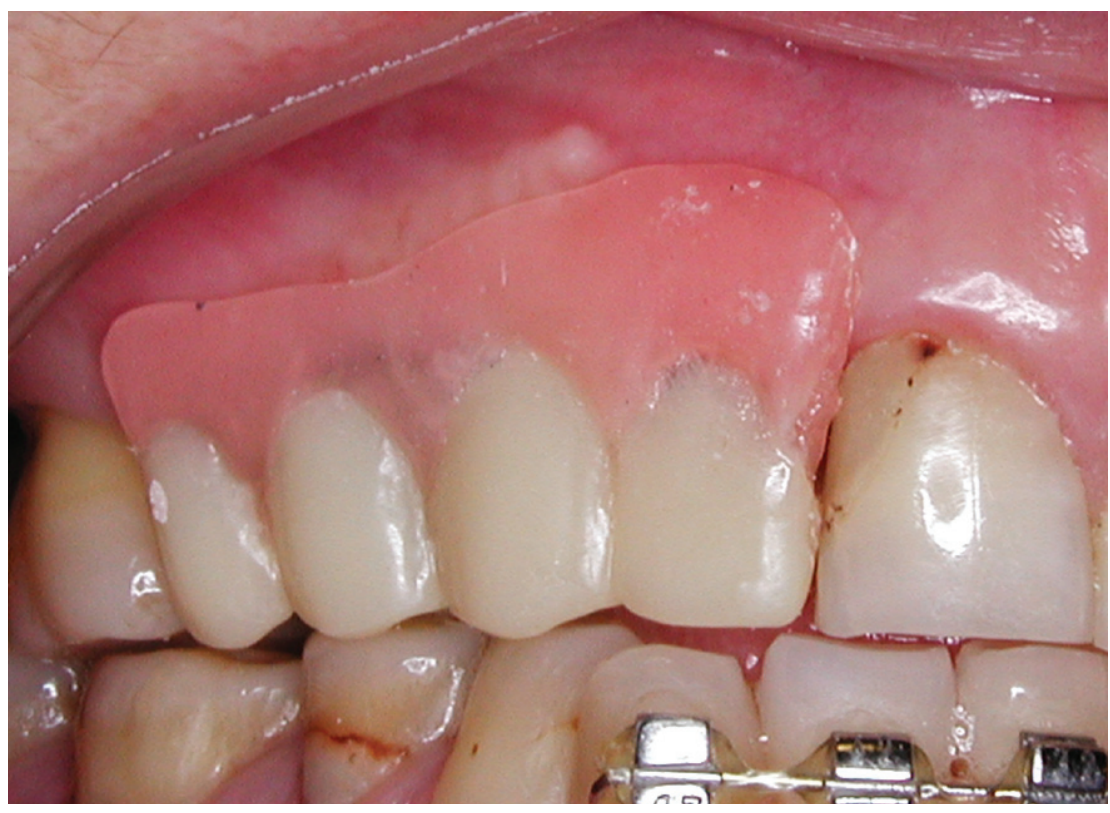

Figura 1. Provisional envolvente en boca. Vista frontal.

\section{Objetivos}

1. Provocar crecimientos gingivales localizados con la utilización de una prótesis provisional original, diseñada a tal efecto.

2. Diseñar un dispositivo para la medición de variaciones de presión en el interior de pequeñas cavidades incolapsables y no herméticas colocadas paragingivalmente, delimitadas por un provisional envolvente.

3. Llevar a cabo mediciones manométricas en el interior de dichas cavidades.

\section{Material u método}

Para este estudio preliminar se seleccionó un individuo, mujer de 64 años de edad, no fumadora, con una higiene oral aceptable (se midió el índice de placa al comienzo y al término de la experiencia). Se confeccionó un formulario donde recogeríamos los datos del sujeto, como el biotipo gingival, presencia de parafunciones, fumador o no, edad, sexo, y también los registros que obtuvimos.

La paciente no tomaba ninguna medicación, ni presentaba ningún antecedente familiar o personal que puediera interferir con nuestro trabajo. Fue informada suficientemente del estudio, prestando su consentimiento informado.

La zona sujeta a nuestra experiencia fue el tramo desdentado correspondiente al primer cuadrante, donde la prótesis parcial extraible que llevaba había dejado un perfil gingival totalmente aplanado. El nivel gingival de las papilas, en general, era de ligera pérdida, atribuible a la edad de la paciente, y siguiendo la hipótesis inicial, perpetuado por la pérdida de tonicidad labial (mayor facilidad para el colapso de la tronera por parte de los labios y la lengua).

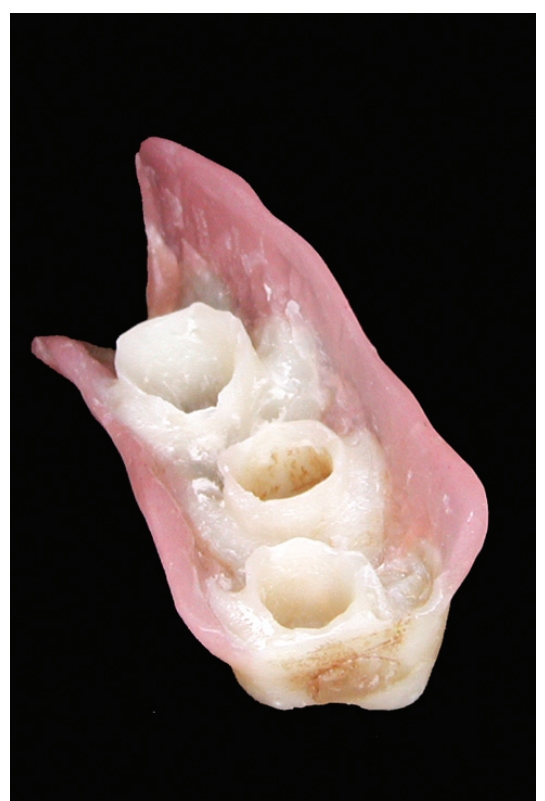

Figura 2. Provisional envolvente. Vista gingival.

Se colocaron implantes ITI Straumann ${ }^{\circledR}$ en los lugares indicados, sobre los que roscamos muñones para el posterior cementado de la prótesis, mediante carga convencional diferida.

El diseño del provisional se basó en el cierre de las troneras artificialmente, pero dejando una cavidad en el interior del provisional que respetara un espacio para el nuevo tejido gingival. La cavidad se hizo todo lo amplia que los muñones sobre implantes, el tejido gingival existente y la resina que se colocó formando las barreras vestibular y palatina, permitieron. Se buscaba ganar un volumen de encía que posteriormente se modelaría con las formas axiales de la prótesis definitiva.

Primero se construyó un provisional convencional sobre los muñones ITI, utilizando una llave de silicona (Zetalabor Hard de Zhermark ${ }^{\circledR}$ ) y resina para provisionales (Temporary Cold.V de 


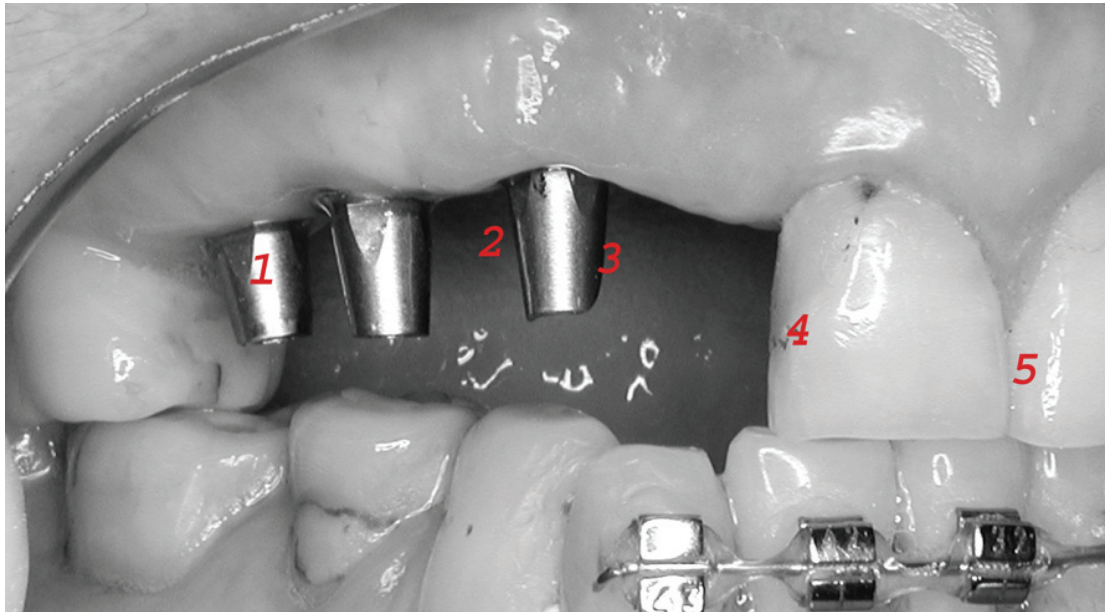

Figura 3. Representación de los 5 puntos de medición gingival para la experiencia.

Major $\AA)$. Luego se añadió resina rosa autopolimerizable (Pro-Base Cold de Ivoclar () , conformando las paredes vestibular y palatina para impedir el colapso de los tejidos (fig. 1).

Posteriormente, se vaciaron de resina aquellas zonas que la disposición de los muñones permitieron: zonas interimplante y la zona del póntico 1.2 (fig. 2).

La retención del provisional fue mediante fricción; de este modo, la paciente lo retiraba cada noche para del provisional, completando la higiene con gel de clorhexidina al 0,12\% (Periokin gel de Kin $®$ ) que colocaba en el interior de las cavidades del provisional, y enjuagues a base de triclosán (Lacer Oros de Lacer $\circledast$ ).

La zona del provisional adyacente al 1.1 se acabó de modelar con composite fluido (Tetric Flow de Ivoclar Vivadent $₫)$, para acabar de conseguir esta cavidad incolapsable pero no hermética. proceder a la limpieza de su boca y la
La mediciones se realizaron con una sonda periodontal sobre los siguientes puntos de registro en cada control (fig.3):

- P1: Desde el punto más oclusal del muñón del implante en zona 1.5i por mesial, al borde gingival.

- P2: Desde el punto más incisal del muñón del implante en zona 1.3i por distal, al borde gingival

- P3: Desde el punto más incisal del muñón del implante en zona 1.3i por mesial, al borde gingival.

- P4: Desde el borde incisal distal del 1.1 hasta el borde gingival.

- P5: Desde el borde incisal mesial del 1.1 hasta la punta de la papila interincisal media.

El seguimiento se prolongó a lo largo de seis meses, durante los cuales se fueron realizando mediciones cada vez que el paciente acudía a control.

Para la confección del dispositivo de medición, se construyó una prótesis muy similar al provisional llevado por la paciente, pero engrosado en la zona del 1.2, donde se insertaría una sonda de manometría intraesofágica.
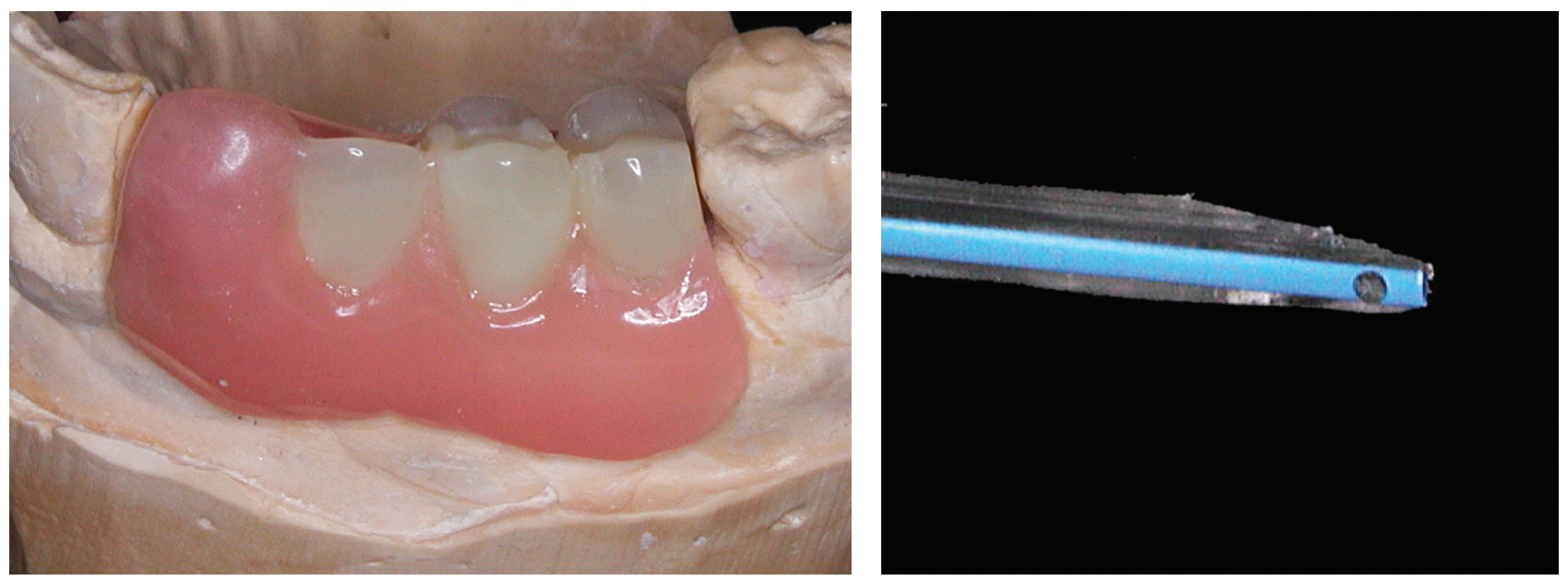

Figura 4. De izquierda a derecha: diseño del dispositivo para medición de variaciones de presión, y cánula de registro. 


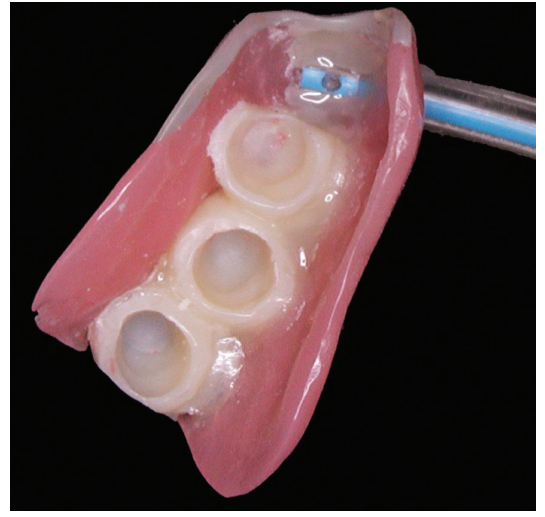

Figura 5. Cánula de registro conectada al dispositivo de medición y dirigida hacia la encía.

Esta sonda consta de 4 luces radiales para medición de la presión, y libera agua bidestilada a velocidad constante. Se modificó dicha sonda según nuestras necesidades, inutilizando tres de las luces y recortándola para que quedara la luz efectiva lo más distal posible (fig.4).

Una vez realizado un orificio por vestibular, a nivel del 1.2, se ajustó la cánula con composite fluido (Tetric Flow de Ivoclar Vivadent $\AA$ ), de manera que quedó la luz activa enfocada hacia la encía (fig.5).
Por el otro extremo, la sonda se conectó al aparato de manometría, lo que permitió registrar cualquier variación de presión producida en el interior de la cavidad (fig.6). Para mayor sujeción del dispositivo en la boca, se colocó en el momento de la medición, una ínfima cantidad de silicona fluida (Fit Checker II de GC Corporation ${ }^{\circledR}$ ).

\section{Resultados}

\section{Día 0}

Las mediciones correspondientes al punto de partida fueron las siguientes: P1: $4 \mathrm{~mm}, \mathrm{P2}: 4 \mathrm{~mm}, \mathrm{P3}: 4 \mathrm{~mm}$, P4: $7 \mathrm{~mm}, \mathrm{P5}: 4 \mathrm{~mm}$.

Los datos obtenidos se complementaron con la observación visual (figs. 7-8):

- la obturación en distal del 1.1 presenta tres puntos de tinción en la zona más gingival, a día 0 , la encía alcanzaba el segundo punto de la obturación.

- Ios muñones ITI presentan facetas aplanadas en el tercio gingival de sus paredes axiales, en el implante 1.3i por mesial, está prácticamente al descubierto.

\section{Día 7}

En siete días, la faceta aplanada del implante quedó cubierta, y la futura papila entre 1.2 y 1.1, casi alcanzaba el tercer punto de tinción de la obturación distal del 1.1 (fig.9).

Las mediciones correspondientes al control de la semana fueron las siguientes: P1: 4mm, P2: 4mm, P3: $3 \mathrm{~mm}, \mathrm{P} 4: 6 \mathrm{~mm}, \mathrm{P} 5: 4 \mathrm{~mm}$.

\section{Día 15}

Los resultados obtenidos a las mediciones correspondientes a los 15 días fueron: P1: 3,5mm, P2: 4mm, P3: $3 \mathrm{~mm}, \mathrm{P} 4: 5 \mathrm{~mm}$, P5: $4 \mathrm{~mm}$.

\section{Día 21}

El resultado de las mediciones fue el siguiente: P1: $3,5 \mathrm{~mm}, \mathrm{P} 2: 4 \mathrm{~mm}$, P3: 3mm, P4: 5mm, P5: 4mm.

Las variaciones fueron más evidentes en la zona del 1.2. En 21 días, la encía sobrepasó el tercer punto de tinción.

En la figura 10 se observa cómo quedó una porción de encía hacia vestibular de los muñones, delimitada por la prótesis provisional, ya que ésta presentaba unos márgenes de resina
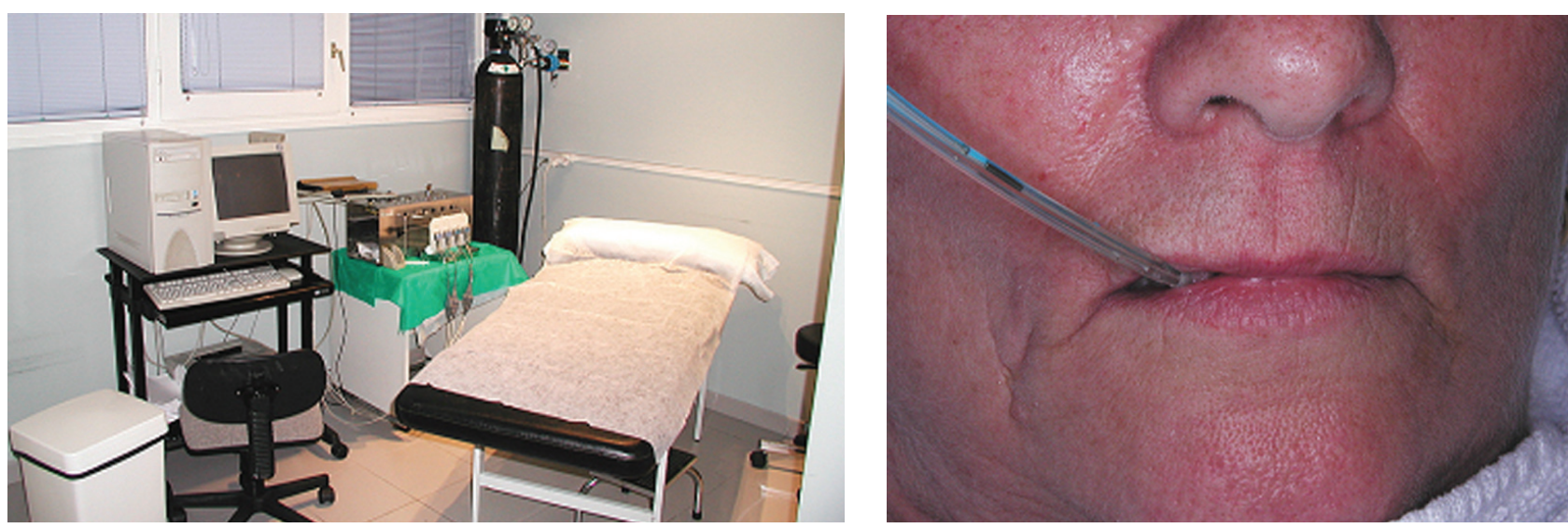

Figura 6. De izquierda a derecha: máquina de manometrías intraesofágicas y cánula conectada al dispositivo de medición permitiendo el sellado labial. 


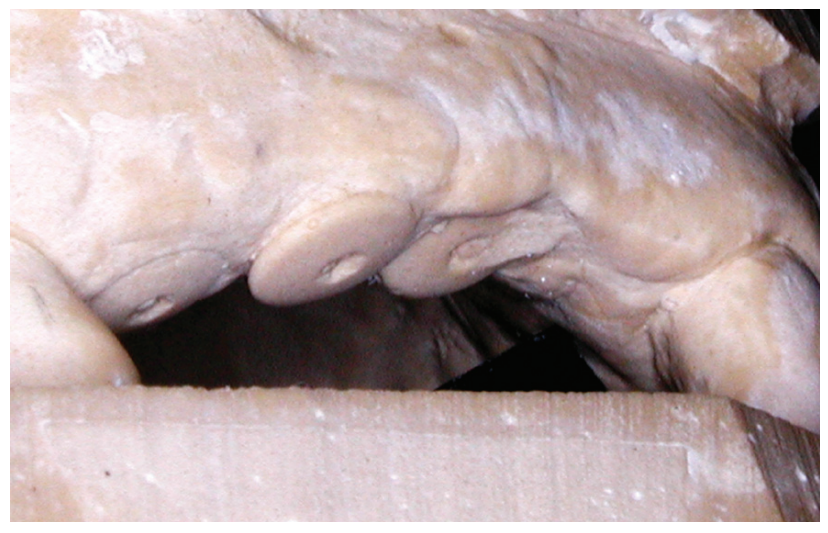

Figura 7. Situación inicial. Modelo de yeso.

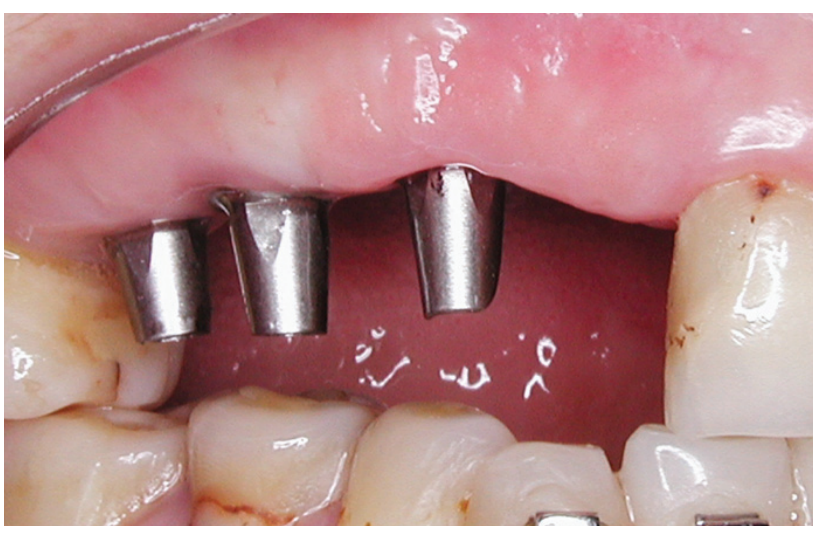

Figura 8. Control día 0. Vista frontal.

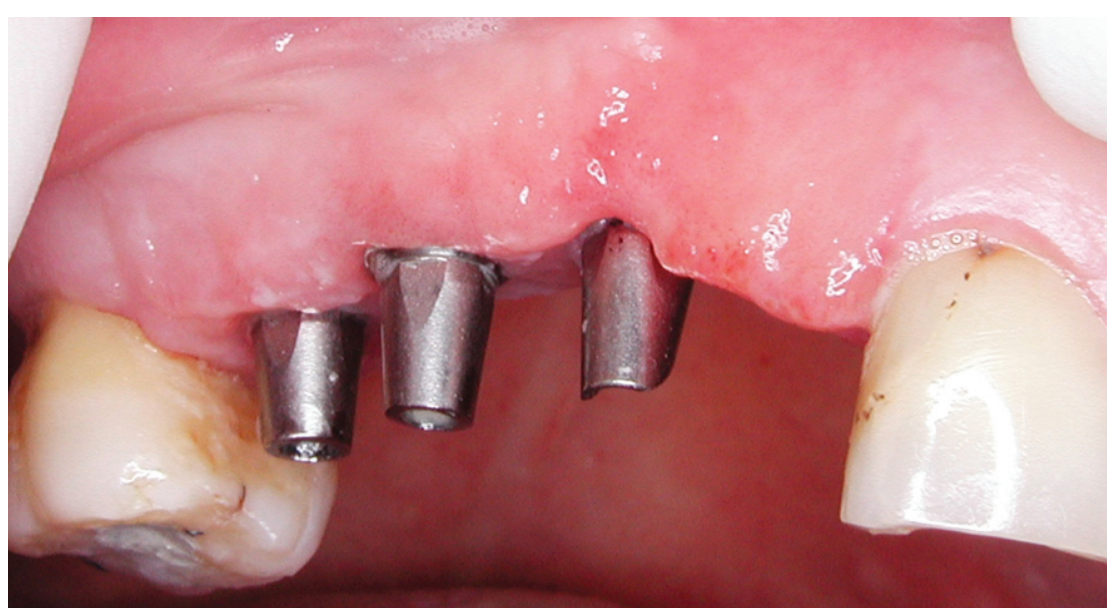

Figura 9. Control dia 7. Vista frontal. alrededor de los mismos, que hicieron que la encía se conformase ligeramente separada de los muñones.

\section{Día 36}

Los resultados en este control fueron los siguientes: $\mathrm{P} 1: 3,5 \mathrm{~mm}, \mathrm{P} 2$ : 4mm, P3: 3mm, P4: 5mm, P5: 4mm (fig 11).

\section{Día 57}

Los resultados obtenidos en este control fueron: P1: $3 \mathrm{~mm}, \mathrm{P} 2$ : $4 \mathrm{~mm}$, P3: $3 \mathrm{~mm}, \mathrm{P4}$ : $5 \mathrm{~mm}, \mathrm{P5}: 4 \mathrm{~mm}$.
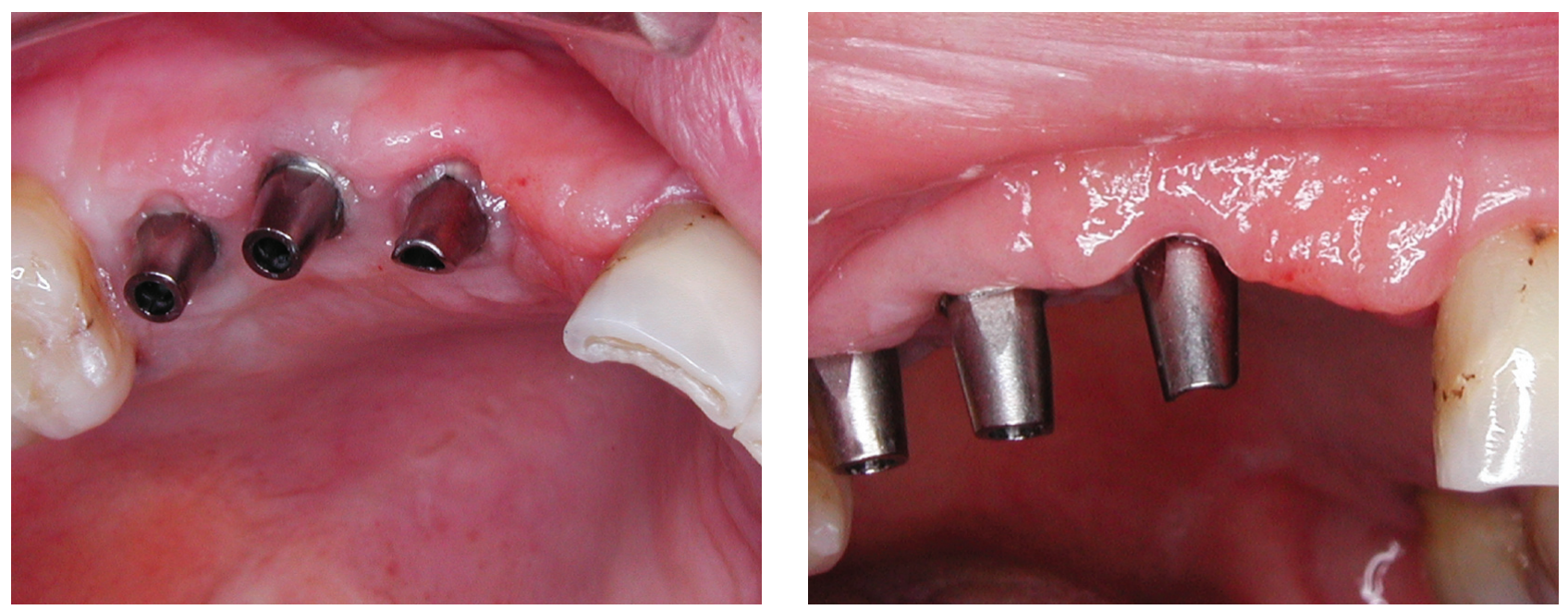

Figura 10. Control día 21. De izquierda a derecha, vista oclusal y frontal.

RCOE, 2005, Vol 10, No2, 145-157 

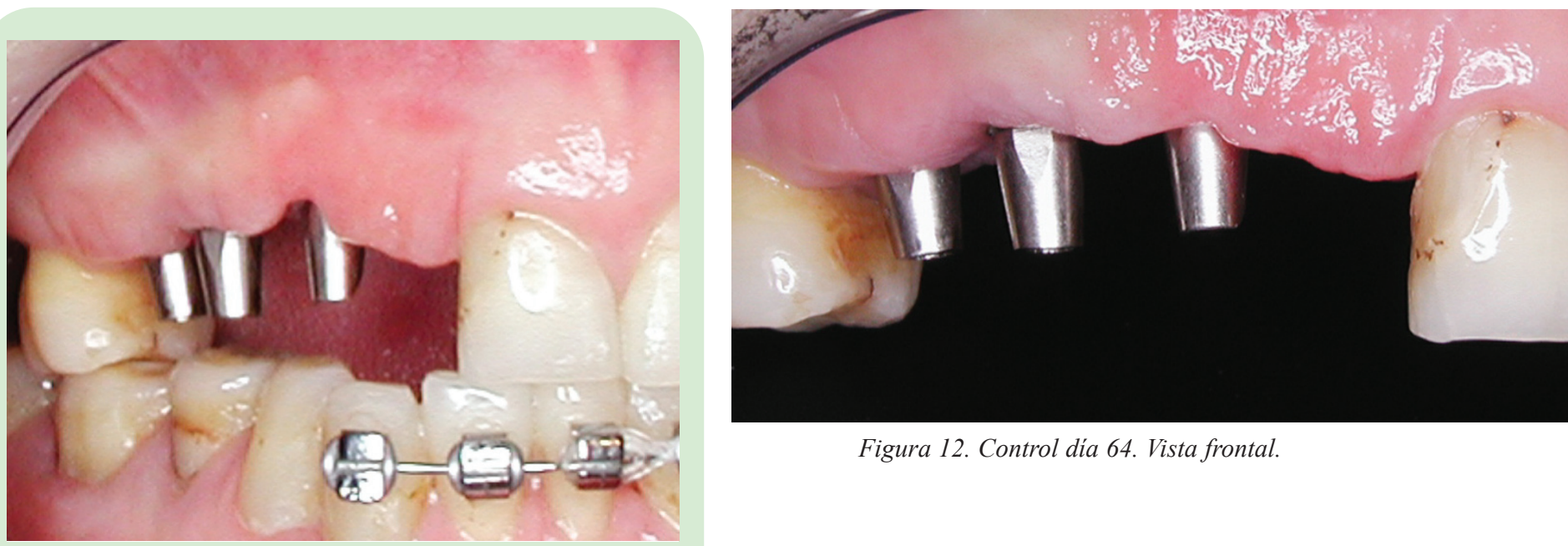

Figura 12. Control día 64. Vista frontal.
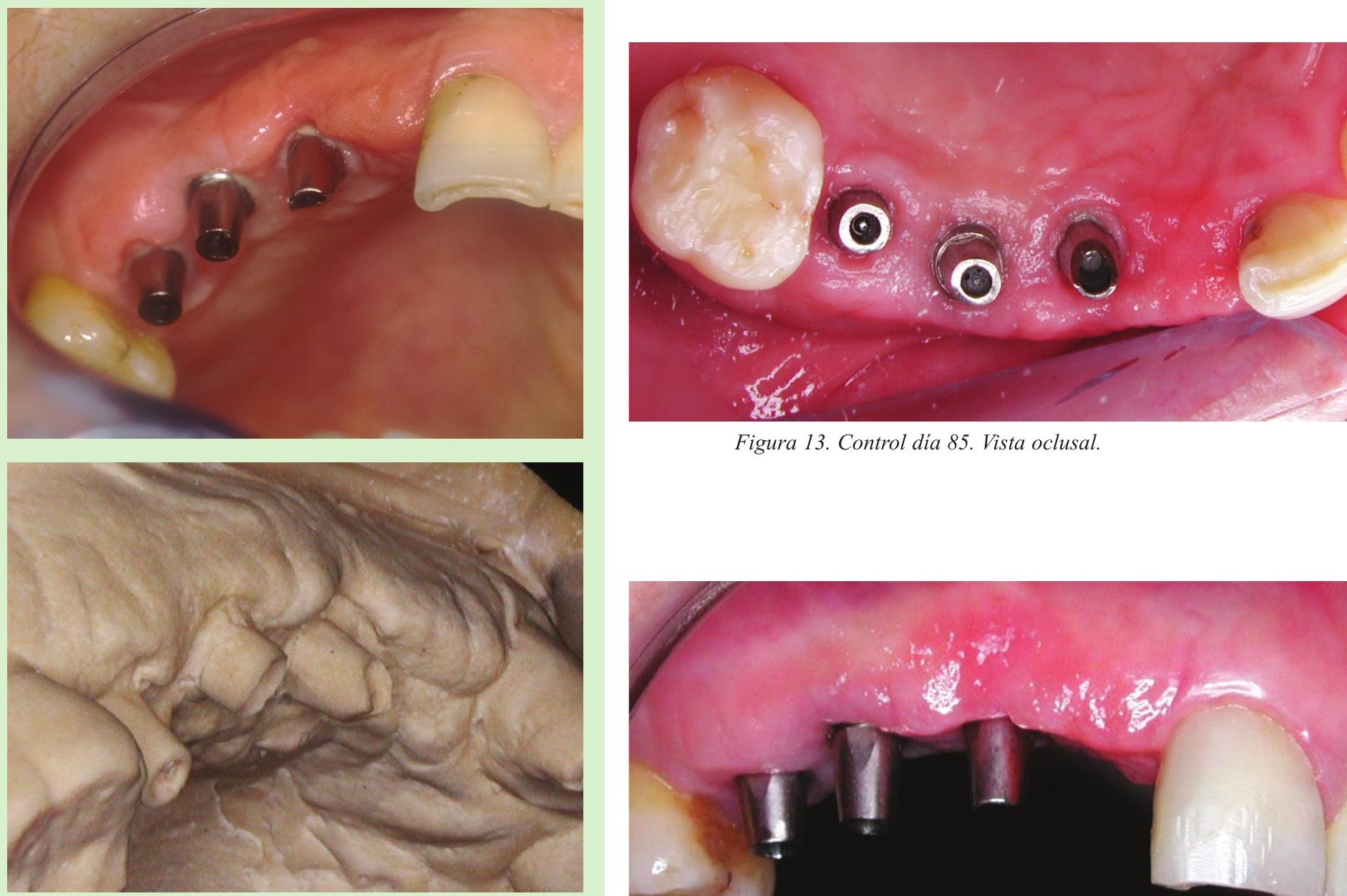

Figura 11. Control día 36. De arriba a abajo, vista frontal, oclusal y modelo de yeso.

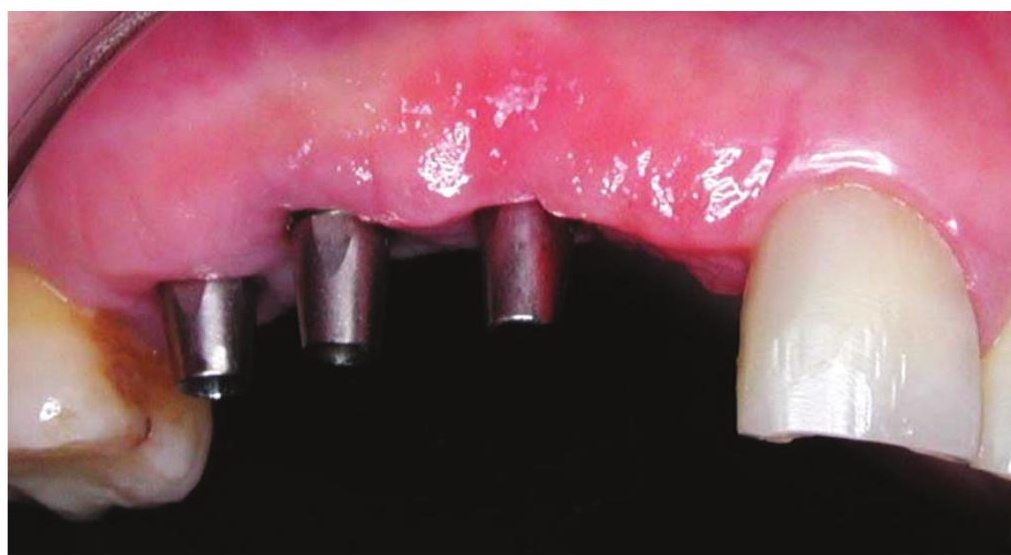

Figura 14. Control día 85. Vista frontal.

RCOE, 2005, Vol 10, N02, 145-157 


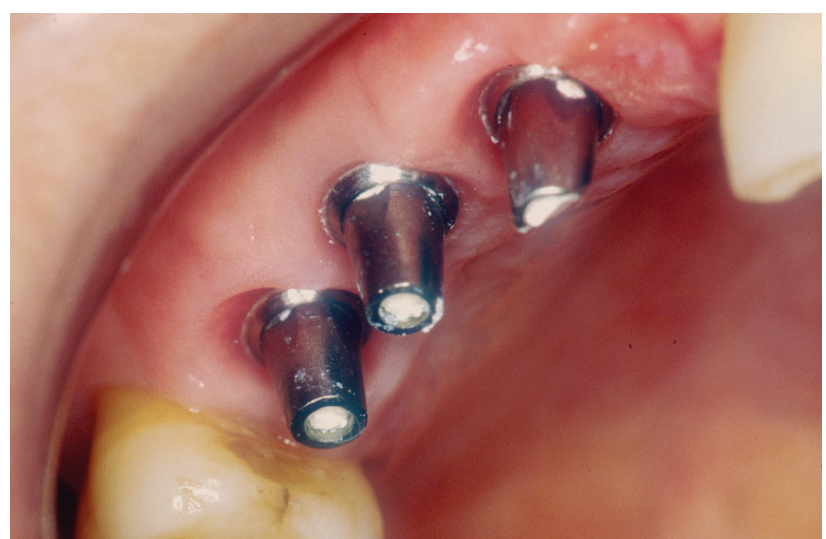

Figura 15. Control día 92. Vista oclusal.

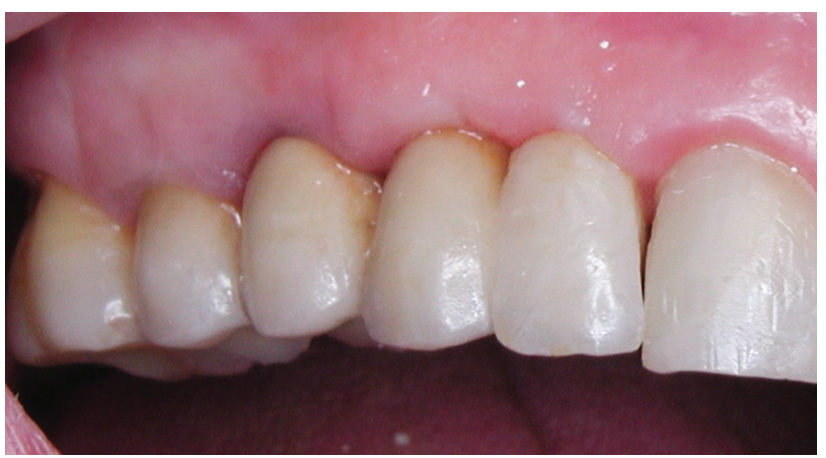

Figura 16. Control día 134. Vista frontal con prótesis definitiva.

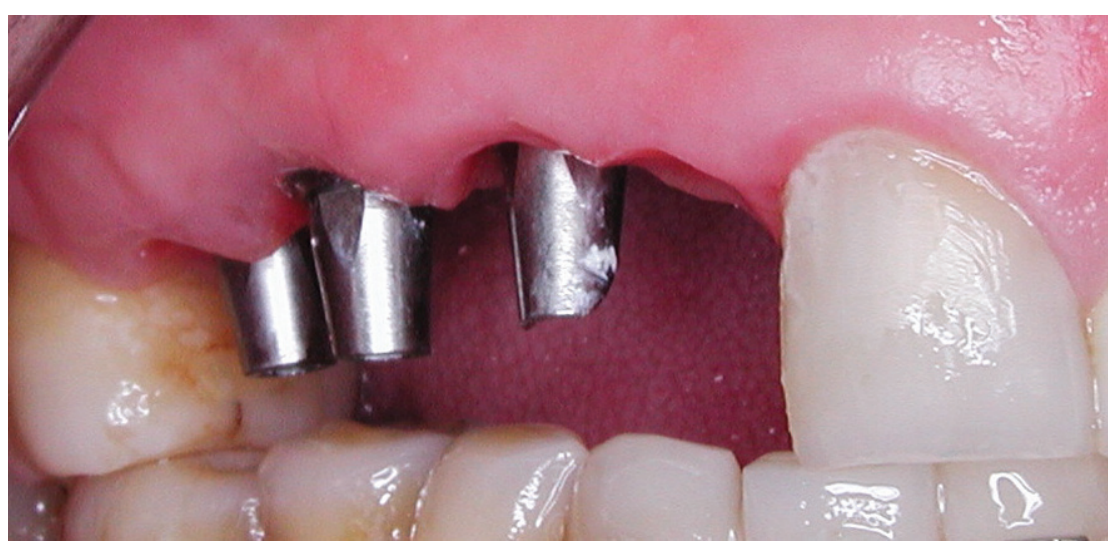

Figura 17. Control día 191. Vista frontal.

\section{Día 64}

Se obtuvieron los siguientes datos: P1: $3 \mathrm{~mm}, \mathrm{P2}$ : $3 \mathrm{~mm}, \mathrm{P3}: 3 \mathrm{~mm}, \mathrm{P4}$ : 5mm, P5: $4 \mathrm{~mm}$ (fig. 12)

\section{Día 85}

Estos fueron los resultados numéricos: $\mathrm{P} 1: 3 \mathrm{~mm}, \mathrm{P} 2: 3 \mathrm{~mm}, \mathrm{P} 3: 2,5 \mathrm{~mm}$, P4: $5 \mathrm{~mm}, \mathrm{P5}: 4 \mathrm{~mm}$.

Se adelgazaron las paredes del provisional situadas sobre la superficie de Ios pilares ITI, la encía circundante se remodeló en repuesta, cerrándose más sobre los mismos y disimulando el aspecto mamelonado que presentaba en una vista oclusal (fig. 13). El festoneado gingival vestibular del implante 1.3i se había suavizado (fig.14).

\section{Día 92}

Pasados tres meses, se colocó la prótesis definitiva cementada provisionalmente, lo que provocó una compresión alrededor de los implantes de los tejidos blandos creados, y también en la zona póntica del 1.2. Esta compresión se mantuvo estable en los
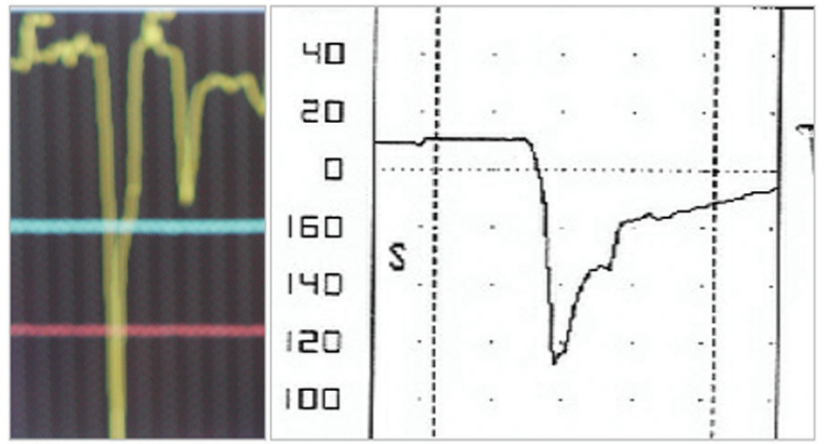

Figura 18. Manometría representativa de la maniobra de deglución seca.

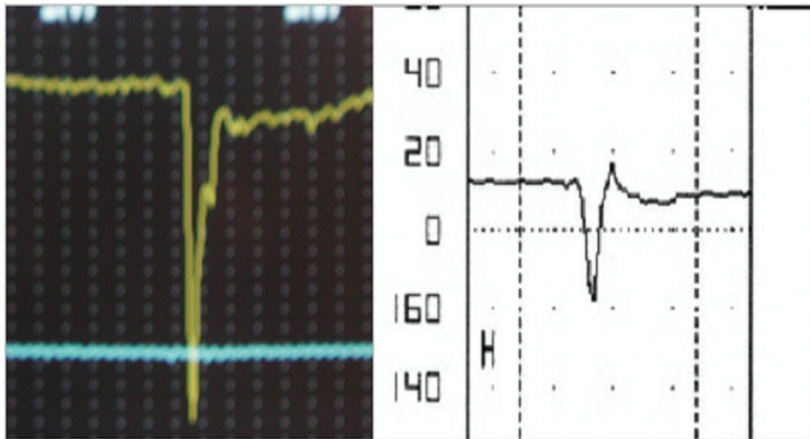

Figura 19. Manometría representativa de la maniobra de deglución húmeda. 


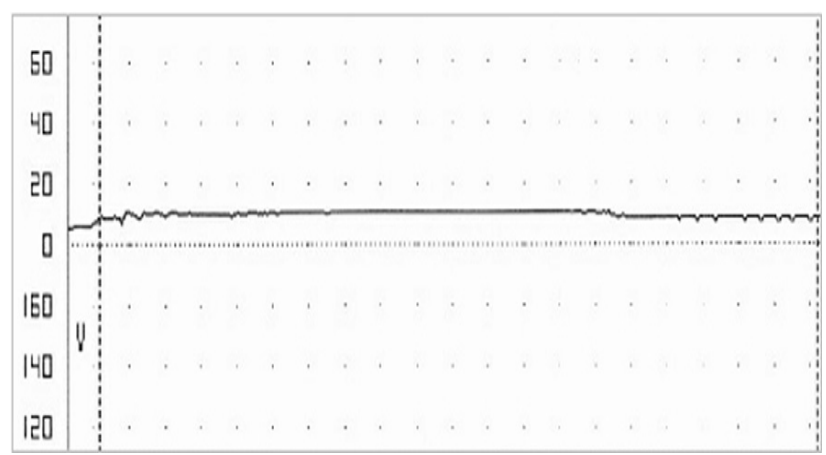

Figura 20. Manometría representativa de la maniobra de Valsalva.

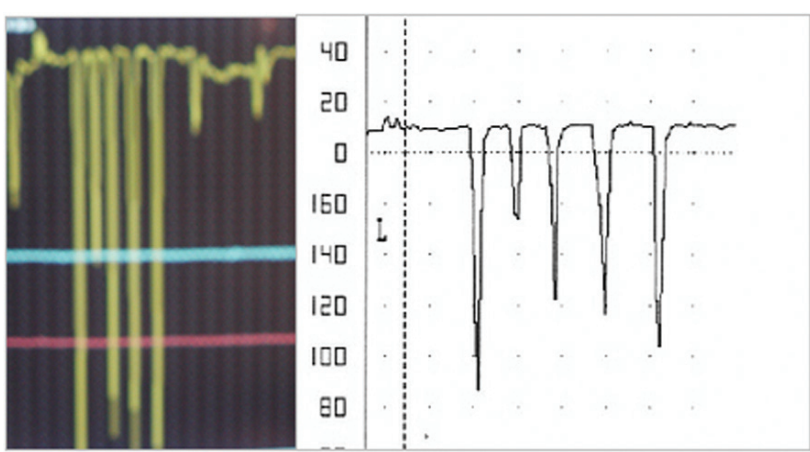

Figura 21. Manometría representativa de la maniobra de apertura y cierre labial bruscos. siguientes controles, no produciéndose mayor retracción de los tejidos (fig. 15).

Tras las mediciones se obtuvieron estos resultados: P1: $3 \mathrm{~mm}, \mathrm{P} 2: 3 \mathrm{~mm}$ P3: 3mm, P4: 6mm, P5: 4mm.

\section{Día 134}

En el siguiente control, se obtuvieron las siguientes mediciones: $\mathrm{P} 1$ : $3 \mathrm{~mm}, \mathrm{P} 2: 3 \mathrm{~mm}, \mathrm{P3}: 3 \mathrm{~mm}, \mathrm{P} 4: 6 \mathrm{~mm}$, P5: 4mm (fig. 16).

\section{Día 162}

Se observó una mayor definición en el perfil gingival a la vez que una insinuación entre 1.2 y 1.1. Las mediciones dieron los siguientes datos: $\mathrm{P} 1$ : $3 \mathrm{~mm}, \mathrm{P2}: 3 \mathrm{~mm}, \mathrm{P3}: 3 \mathrm{~mm}, \mathrm{P} 4: 6 \mathrm{~mm}$, P5: $4 \mathrm{~mm}$.

\section{Día 191}

Tres meses después de la colocación de la prótesis definitiva, el nivel de crecimiento gingival, era estable, insinuándose en los espacios interdentales. Márgenes gingivales más definidos, se acentúan las papilas. Mediciones: P1: $3 \mathrm{~mm}, \mathrm{P} 2$ : $3 \mathrm{~mm}, \mathrm{P} 3$ : $3 \mathrm{~mm}, \mathrm{P} 4: 5,5 \mathrm{~mm}, \mathrm{P5}: 4 \mathrm{~mm}$ (fig. 17)

Junto con la «Unitat de Motilitat del Servei de Digestiu de I'Institut Univer- sitari Dexeus», se realizó una prueba manométrica para evidenciar las variaciones de presión dentro de la cavidad practicada en la zona del 1.2 (zona desdentada), con un dispositivo similar al empleado como prótesis provisional, ya descrito anteriormente.

Se realizaron diferentes maniobras siguiendo un protocolo realizado por la Unidad de Motilidad, tales como deglución seca (tragar saliva), deglución húmeda (3 cc de agua), maniobra de Valsalva (con y sin oclusión nasal), cerrar los labios y separarlos bruscamente, y soplar. Cada maniobra se repitió diez veces, espaciando las repeticiones diez segundos. Tras calibrar la máquina obteniendo una presión basal de $8 \mathrm{mmHg}$, los resultados mínimos medios obtenidos (igualando la basal a 0) para las distintas maniobras fueron los siguientes:

- Deglución seca: -40 mmHg (fig. 18).

- Deglución húmeda: -25mmHg (fig. 19).

- Maniobra de Valsalva: 4 mmHg. No se apreciaron diferencias significativas al realizar la maniobra de Valsalva con oclusión nasal o libre (fig. 20).

- Cerrando los labios y abriéndolos bruscamente: $-66 \mathrm{mmHg}$ (fig. 21).

\begin{tabular}{|lccccc}
\hline \multicolumn{5}{|c}{ Tabla de mediciones } \\
\hline & P1 & P2 & P3 & P4 & P5 \\
\hline Día 0 & 4 & 4 & 4 & 7 & 4 \\
\hline Día 7 & 4 & 4 & 3 & 6 & 4 \\
\hline Día 15 & 3.5 & 4 & 3 & 5.5 & 4 \\
\hline Día 21 & 3.5 & 4 & 3 & 5 & 4 \\
\hline Día 36 & 3.5 & 4 & 3 & 5 & 4 \\
\hline Día 57 & 3 & 4 & 2 & 5 & 4 \\
\hline Día 64 & 3 & 3 & 3 & 5 & 4 \\
\hline Día 85 & 3 & 3 & 2.5 & 5 & 4 \\
\hline Día 92 & 3 & 3 & 3 & 6 & 4 \\
\hline Día 134 & 3 & 3 & 3 & 6 & 4 \\
\hline Día 162 & 3 & 3 & 3 & 6 & 4 \\
\hline Día 191 & 3 & 3 & 3 & 5.5 & 4 \\
\hline
\end{tabular}

Figura 22. Tabla de las mediciones recogidas en milimetros en los distintos puntos de registro.

- Presión media en espiración: 18 $\mathrm{mmHg}$.

Los cambios más evidentes se observaron durante los primeros 15 días, produciéndose después pequeñas variaciones en respuesta a las modificaciones que se llevaron a cabo en el provisional (fig. 22). Es significativo observar la comparativa entre el modelo de yeso correspondiente al día 0 y al día 36 (fig. 23). La figura 24 


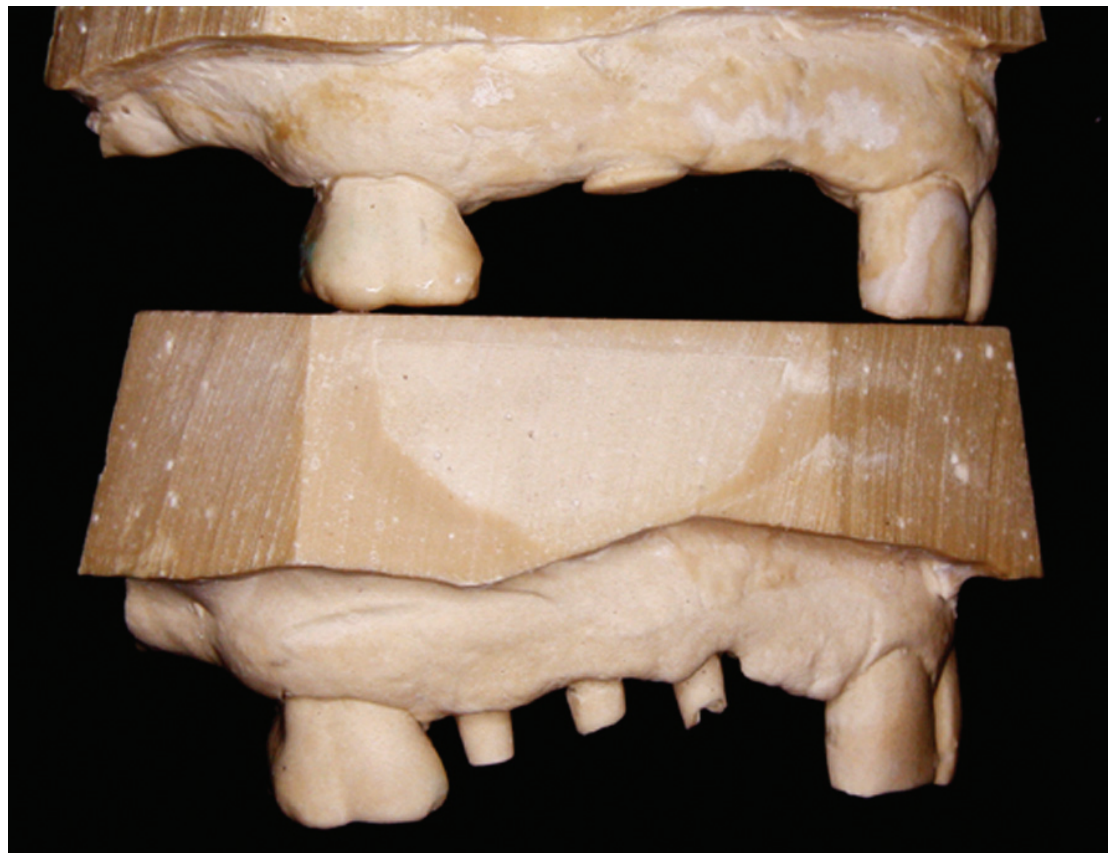

Figura 23. Comparativa de modelos en yeso tomados el día 0 (superior) y el 36 (inferior).

representa el crecimiento gingival obtenido en el tiempo, y también la compresión en valores negativos que provocó la inserción de la prótesis definitiva, haciendo balance del crecimiento neto final.

La obtención de resultados positivos en la manometría evidencia que en interior de la cavidad oral se producen variaciones de presión durante la deglución, y en diversas maniobras realizadas, que afectan a los tejidos blandos implicados. Estas fluctuaciones de presión se hacen evidentes en el interior de cavidades paragingivales incolapsables pero no herméticas, delimitadas por provisionales envolventes, en el interior de las cuales se puede obtener crecimiento gingival que no obtendríamos habitualmente con provisionales convencionales, al dejar éstos que el vacío generado colapse los espacios interdentales $y$, en general, el resto de la cavidad oral.

\section{Discusión}

En la literatura, las experiencias referentes a variaciones de presión en la cavidad oral son todas ellas en relación a cambios registrados bajo prótesis completas maxilares, pero no hay datos de unas variaciones de presión al margen de este tipo de prótesis. En el pasado se llegaron a confeccionar prótesis completas con cámaras de succión a fin de ganar retención, cámaras que según Gay ${ }^{3}$, pueden ser causa de comunicaciones oro-sinusales por perforación de la bóveda palatina. Consecuencias menores que ésta eran la irritación de la mucosa o los sobrecrecimientos gingivales. Estos

\begin{tabular}{|c|c|c|c|c|c|}
\hline & & ¿ᄃక & |l| & & \\
\hline & P1 & P2 & P3 & P4 & P5 \\
\hline Día 0 & 0 & 0 & 0 & 0 & 0 \\
\hline Día 7 & 0 & 0 & 1 & 1 & 0 \\
\hline Día 15 & 0,5 & 0 & 0 & 0,5 & 0 \\
\hline Día 21 & 0 & 0 & 0 & 0,5 & 0 \\
\hline Día 36 & 0 & 0 & 0 & 0 & 0 \\
\hline Día 57 & 0,5 & 0 & 0 & 0 & 0 \\
\hline Día 64 & 0 & 1 & 0 & 0 & 0 \\
\hline Día 85 & 0 & 0 & 0,5 & 0 & 0 \\
\hline Día 92 & 0 & 0 & $-0,5$ & 0 & 0 \\
\hline Día 134 & 0 & 0 & 0 & -1 & 0 \\
\hline Día 162 & 0 & 0 & 0 & 0 & 0 \\
\hline Día 191 & 0 & 0 & 0 & 0,5 & 0 \\
\hline Aumento & & & & & \\
\hline total & $1^{\prime \prime}$ & $1^{\prime \prime}$ & $1,5^{\prime \prime}$ & $2,5^{\prime \prime}$ & 0" \\
\hline $\begin{array}{l}\text { Compresi } \\
\text { tras inser }\end{array}$ & ión & & & & \\
\hline definitivo & $0^{\prime \prime}$ & $0^{\prime \prime}$ & $-0,5^{\prime \prime}$ & $-1^{\prime \prime}$ & 0" \\
\hline Crecimier & & & & & \\
\hline neto & $1^{\prime \prime}$ & $1^{\prime \prime}$ & $1^{\prime \prime}$ & $1,5^{\prime \prime}$ & )" \\
\hline
\end{tabular}

Figura 24. Tabla que recorre el crecimiento ginginal obtenido a lo largo de la experiencia expresado en milímetros.

crecimientos no son comparables con el aumento de volumen gingival obtenido en esta experiencia clínica, ya que bajo una prótesis completa, los tejidos están sometidos a estrés mecánico, y al acúmulo de placa, que introduce un componente irritativo. En nuestra experiencia descrita no hay ningún tipo de estrés mecánico, ya que la prótesis provisional se apoya sobre los muñones de los implantes, y no sobre la mucosa.

Este tipo de circunstancias observadas en pacientes portadores de prótesis completas maxilares, llevó a la realización de estudios como el de Cutright ${ }^{4}$ 
en 1976, quien describió cambios de presión bajo prótesis completas maxilares en cuatro individuos, durante trabajo masticatorio, en reposo, deglución seca, deglución húmeda, fumando (en uno de los sujetos), etc. En las prótesis totales extraibles la retención corre a cargo de la adaptabilidad de las superficies (mucosa y protésica) y un buen sellado periférico. Cutright ${ }^{4 *}$ recogió cuatro puntos de medición en las prótesis:

- Reborde alveolar derecho.

- Reborde alveolar izquierdo.

- Paladar anterior.

- Paladar posterior.

Los resultados se expresaron en $\mathrm{mm}$ de $\mathrm{Hg}$, por debajo o por encima de 0 (tomado el punto 0 la presión basal en reposo, equivalente a los 8 $\mathrm{mmHg}$ de nuestra experiencia). En procesos masticatorios obtuvo variabilidad interindividual e intraindividual, acusando esta variabilidad al patrón masticatorio individual. Los valores de máxima presión positiva fueron obtenidos para la maniobra masticatoria con cacahuetes, 140 $\mathrm{mmHg}$, destacando que inmediatamente después del aumento de presión se producía una presión por debajo del punto 0 de $-10 \mathrm{mmHg}$. En todos los puntos de medición y en todos los individuos obtenía bajadas de presión posteriores a la fuerte subida de presión que provocaban las maniobras masticatorias, aunque con resultados muy variables.

Una prótesis completa superior que presente un correcto sellado periférico, al asentar sobre la mucosa y entrar en función, da lugar bajo la misma a una cavidad virtual ocupada por saliva, que genera un vacío sobre la mucosa de apoyo, tal y como estu- dió Cutright ${ }^{4 *}$. Debido al sellado periférico, los valores que se registren bajo esta prótesis no se pueden equiparar a los del resto de la cavidad oral, puesto que funciona en la práctica, como un compartimento independiente.

Una prótesis completa en función, provoca un bombeo sobre la mucosa, la presiona (presión positiva), y luego debido a la resilencia de la mucosa oral, recupera su posición (presión negativa). Se trata pues de un bombeo generado por una acción mecánica, por lo que los resultados no son comparables con los provocados en nuestra experiencia ni con los que pueden darse en la cavidad oral en situación de ausencia de esas prótesis.

La cavidad delimitada por el «provisional envolvente», no puede estar sometida a ningún tipo de trabajo mecánico o bombeo, por el apoyo sobre los muñones de los implantes, y guardan una comunicación con la cavidad oral, ya que no hay un sellado con la mucosa tal que provoque el aislamiento, sufriendo de este modo los cambios de presión que se produzcan en la misma, sin por ello querer decir que los valores numéricos obtenidos sean trasladables a toda la cavidad.

La experiencia de Cutright $^{4^{*}}$ no dejó evidencia de la presencia de un vacío en la cavidad oral en condiciones normales y evidenciable en una serie de maniobras, sino sólo demostró que bajo prótesis completas maxilares (con un sellado periférico) se producía una cámara sometida a fluctuaciones de presión. Estas fluctuaciones, se producían en diferente medida durante maniobras masticatorias y no masticatorias, ya que también observó fluctuaciones en deglu- ción seca y húmeda. Destacando que:

1. En maniobras masticatorias eran mayores las presiones positivas (provocadas por la oclusión contra la prótesis) que las negativas (provocadas por la resilencia de la mucosa).

2. En maniobras no masticatorias como degluciones secas o húmedas eran mayores los valores negativos (vacío que tira de la prótesis tratando de despegarla), que los positivos (apoyo lingual, labial, contacto dentario,...).

3. El habla y fumar un cigarrillo provocaban también variaciones de presión bajo la prótesis completa.

En nuestro trabajo también se registraron variaciones de presión durante el habla; no obstante, no se obtuvieron valores positivos altos similares a los de Cutright ${ }^{4 *}$, ya que las fluctuaciones en el interior del provisional se producían por continuidad con la cámara oral y no por un trabajo mecánico sobre el mismo (5-6 $\mathrm{mmHg}$ sobre la basal de $8 \mathrm{mmHg}$ ).

Un dato que apoya el uso diurno del «provisional envolvente» para lograr un incremento de volumen gingival, es que, tal como apunta Ockeson ${ }^{5}$, el número de degluciones durante el día es muy superior al producido durante el sueño, donde baja considerablemente la actividad deglutora, ya que de los 590 ciclos deglutorios que se producen en 24 horas, 146 se llevan a cabo durante las comidas, 394, entre comidas y sólo 50 del total de ciclos tienen lugar durante el sueño. Cutright $^{4^{*}}$ registró 23 degluciones durante 15 minutos en un sujeto mientras leía relajadamente el periódico. De este modo, si la boca es un motor que genera vacío, y este vacío influye en el crecimiento de tejido blando en el 
interior de la cavidad oral, si buscamos este efecto, el dispositivo diseñado parece evidente que debería ser de uso, al menos, diurno.

Otro estudio que introdujo el concepto de vacío en la cavidad oral fue el de Grossman', en 1990, quien estudió la respuesta del epitelio oral en monos, bajo condiciones de vacío similares a las que se producen bajo dentaduras completas maxilares. Para ello estudió tres zonas:

1. Epitelio del paladar duro.

2. Epitelio de la encía del reborde alveolar.

3. Epitelio de la mucosa alveolar.

Tomó una impresión de un maxilar desdentado que luego recolocó en el maxilar, y a la que conectó un tubo generando un vacío constante de -80 $\mathrm{mmHg}$. En las zonas 1 y 2 , se produjo un aumento de espesor del epitelio, mientras que en la zona 3, disminuyó el espesor. En la zona 1, bajó la densidad celular, mientras que en las zonas 2 y 3 aumentó. La zona 3, cerca de la línea mucogingival registraba datos variables.

Grossman ${ }^{6}$ demostró, pues, que un vacío de $-80 \mathrm{mmHg}$ provocaba cambios en el epitelio oral, que están directamente relacionados con los requerimientos funcionales de la zona.

A cerca de cambios histológicos bajo prótesis completas maxilares, Akbay ${ }^{7}$ realizó un estudio, en 1988, sobre biopsias de mucosas palatales bajo prótesis totales extraibles, donde concluyó que el tejido conectivo subyacente se caracterizaba por neoformación de fibras de colágeno y numerosos fibroblastos, presencia de macrófagos en la lámina propia y zonas perivasculares, y linfocitos y células plasmáticas en número moderado. La disposición celular mostraba espacios intercelulares reducidos y células con retículo endoplasmático y vacuolas numerosas.

Es evidente que hay cambios en el epitelio bajo la prótesis completa, donde se juntan al menos tres factores:

- Estrés mecánico.

- Acúmulo de placa bacteriana.

- Fluctuaciones de presión.

Grossman', en cuyo estudio sólo habría un factor de aumento de vacío (ni mecánico, ni de acumulación de placa bacteriana) no habla de cambios en cuanto a series celulares en los tejidos estudiados, sino sólo en los grosores de las capas epiteliales.

Respecto al manejo del tejido gingival obtenido (amorfo), su manipulación corresponde a las técnicas protésicas empleadas comúnmente en la actualidad y descritas por varios autores, como por ejemplo Kois ${ }^{8^{*}}$, sobre los perfiles de emergencia, o Borges ${ }^{9}$ acerca de la forma de la pieza póntica y cómo comprimir la encía para lograr una buena estética o naturalidad, etc.

En cualquier caso, el vacío oral es un factor más a tener en el conjunto de parámetros que condicionan la formación y el manejo del tejido blando. Tarnow ${ }^{2}$ habló de la relación entre la distancia del punto de contacto a la cresta ósea interdentaria y la existencia o ausencia de papila. Parece lógico apuntar que puntos de contacto más alejados de la cresta, dejan un espacio triangular más amplio que permite, al bajar la presión intraoral y tender a colapsar la cavidad, una mayor aproximación entre mucosa lingual y labial, lo que dificultaría la formación de papila. En cambio, un punto de contacto más hacia gingival dejaría un triángulo menor, más difícil de ocupar por las mucosas labial y lingual, siempre que el tono muscular del no sea demasiado flácido.

Para que se establezcan protocolos al respecto, no obstante, será necesario realizar estudios con una muestra mayor que permita recoger datos comparativos.

\section{Conclusiones}

1. En el interior de cavidades paragingivales incolapsables y no herméticas delimitadas por provisionales envolventes, se producen fluctuaciones de presión entorno a una basal establecida.

2. Estas variaciones de presión se evidencian en diversas maniobras como la deglución seca y húmeda. La simple entrada y salida de aire provoca también este tipo de variaciones aunque más leves.

3. Se ha podido conseguir crecimiento gingival controlado y ausente de inflamación con el uso de «provisionales envolventes» diseñados a tal efecto.

\section{Agradecimientos}

Al Dr. Enrique Vidal y a la Dra. Carmen Peña del Servicio de Digestivo del «nstitut Universitari Dexeus» de Barcelona. 


\section{Bibliografia recomendada}

Para profundizar en la lectura de este tema, el/los autor/es considera/an interesantes los artículos que aparecen señalados del siguiente modo: *de interés ${ }^{*}$ de especial interés.

1**. Harter PN. Mecanismo de crecimiento de la encía. Una teoría funcional no ontológica. Rev Eur Odontoestomatol 2003;15:111-8. Artículo de lectura obligada ya que desarrolla una explicación neumática de conformación tisular, muy útil para comprender la base del presente trabajo.

2. Tarnow DP. The effect of the distance from the contact point to the crest of bone on the presence or absence of the interproximal papilla. J Periodontol 1992;63:995-6

3. Gay CE, Berini LA. Cirugía oral. Madrid: Ergón, 1999:833

4*. Cutright DE, Brudvik JS, Gay WD, Selting WJ. Tissue pressure under complete dentures. Prosthet Dent 1976;35:160-70.
Trabajo importante por ser uno de los pocos estudios que relacionan la protesis con variaciones de presión intraoral. Basado en prótesis completas maxilares, los autores registran los cambios de presión bajo las mismas ante diferentes maniobras.

5. Ockeson JP. Tratamiento de Oclusión y Afecciones Temporomandibulares. St. Louis: Mosby, 1985:54

6. Grossman ES, Forbes ME. Studies related to reaction of supporting soft tissue to denture wear: the histological response of vervet monkey oral epithelium to a $\mathbf{- 8 0}$ mmHg vacuum. J Oral Rehabil 1990; 17:587-97.

7. Akbay T, Akbay C. Ultrastructural investiga- tion of hard palate mucosa under complete dentures. J Prosthet Dent 1988;59:52-8.

$8^{*}$. Kois JC, Kan J. Predictable peri-implant gingival aesthetics: surgical and prosthodontic rationals. Pract Proced Aesthet Dent 2001; 13:691-8.

La importancia de este trabajo radical en la gran importancia del manejo de tejidos en el sector anterior en la odontología estética actual y en las diferentes disciplinas que abordan estos conceptos dentro de la odontología moderna.

9. Borges LJ, Borges AC, Hollweg H, Rodrigues PC. Tissue sculpturing: an alternative method for improving aesthetics of anterior fixed prosthodontics. J Prosthet Dent 1999; 81:630-3. 